\title{
On two interesting industrial prestressed concrete buildings in the Alto Vicentino (1958-1962)
}

\author{
G. Riva ${ }^{1} \&$ F. Steffinlongo ${ }^{2}$ \\ ${ }^{1}$ Dipartimento di Progettazione architettonica, \\ Università Iuav di Venezia, DD 2196, S. Marta, 30123 Venice, Italy \\ ${ }^{2}$ Studio Inge.Co. S. Polo 1868/A 30125 Venice, Italy
}

\begin{abstract}
The 1950s and 1960s witnessed a significant Italian influence on the development of large-scale works in reinforced concrete and prestressed reinforced concrete in several countries around the world. These were built under the guidance of characters such as Pier Luigi Nervi, Riccardo Morandi and Sergio Musmeci. In this period of remarkable evolution in the field of prestressed reinforced concrete - especially in Italy in the area to the north of Vicenza and in particular in Schio, which was already the centre of a great industrial tradition both in textiles and mechanical fields - a number of constructions of remarkable structural strength were built. In the Schio and Valdagno area there is the intention of conducting an in-depth study and comparison of the constructional characteristics of two slender structures covering large spaces with the aim of their re-use: one is the depot of the Assortissaggio on the Lanerossi site in Schio; the other is the industrial complex and weaving room on the Marzotto site in Valdagno.

The insight of the period meant that the structural qualities of the constructions were made evident, leaving the concrete completely exposed; the structural forms were deliberately made simple with a narrow section. At the time of construction the aspects of resistance to environmental actions were not known and, on the other hand, concrete was still perceived as 'artificial rock'. It is probably this way of addressing the structural project - in which the object was conceived as a single system - that led to the high efficiency of these works still evident today. The concrete was used to the limits of its strength; it is clear that higher levels of performance would be required in the future.
\end{abstract}

Keywords: historical pioneering reinforced concrete structures. 


\section{Introduction}

The study of the Assortissaggio construction in the Lanerossi area in Schio, designed by the engineer Bruno Dall'Aglio (full professor of Construction Science at the University of Padua) and built by the Ing. Pio Guaraldo company of Paese, suggests interesting considerations regarding its redevelopment that reinforce the importance of the recent decision to safeguard it from demolition and to use it to hold the company archives.

These considerations also allow the historic value of the building to be placed in the frame of the panorama of the development of industrial buildings in reinforced concrete during the $20^{\text {th }}$ century in the Veneto region and, in particular, in the industrial district of Schio, a town in the area north of Vicenza.

Together with the larger Marzotto plant in Valdagno, the building at the Lanerossi site in Schio seems to conclude the pioneering phase of building in reinforced concrete using on-site casting, inaugurated with the Hennebique patent and reinterpreted in an original way by Italian culture from as early as the 1930s [1] that would develop into the spread of heavy prefabrication from the 1960s. The two works, closely related to each other in that they are development phases of the same design concept, are an example of major technological innovation in terms of the typology employed, the boldness of the structures, the space they cover and the considerable loads they support. However, the most interesting aspect of the 'exceptional performance' of these buildings is the unique coexistence of a 'craft' approach - in terms of both the calculations (done by hand!) of complex structures, and in the production methods using onsite casting in traditional arch frames - and of a design method employing prototypes: basic elements which can be repeated ad infinitum, with low production costs. This was the prelude to prefabrication and to the industrialization of the building site that, soon after, would become the predominant methods of construction.

The designers were doubtless aided by the fact that they were working on industrial buildings and were therefore unaffected by either grandiose plans or the need to create 'communicative' architecture.

\section{The culture of design in post-war Italy}

The creation of the original structure for the Assortissaggio in Schio (19581961) and its 'replica' with the almost coeval construction of the even more challenging Marzotto building in Valdagno (1961-1962) is placed in a very interesting phase of the Italian building industry. In Turin in 1938 Gustavo Colonnetti had already founded the Centro di Studi sui Materiali da Costruzione (Centre for the Study of Construction Materials). In 1948 the first 'regulations regarding prestressed reinforced concrete' were presented. In 1949 the ANICAP (Italian Prestressed Reinforced Concrete Association) was founded. Following the emergency of post-war reconstruction, construction work in reinforced concrete went through one of the most creative phases, enjoying periods of 
profitable relationship between engineering and architecture, as described by Sergio Poretti [2].

Once the pioneering and pragmatic stages were passed, construction in reinforced concrete was based on rigorous assumptions and supported by common interpretative principles, accepted by research commissions at a European level. These regulations made up the basis of future normative prescription of the European Community, still in force today. In Italy the leading figures in the field of this new innovative and creative fervour were the engineers Riccardo Morandi (1902-1989), Pier Luigi Nervi (1891-1979) and Sergio Musmeci (1926-1981) (all three constructed buildings in the Veneto region). They knew - albeit in very different but effective ways - how to express the ideas of an original Italian school, both in the theoretical field and in that of construction, which were internationally recognized.

\section{Industrial constructions in reinforced concrete in the Schio and Valdagno areas}

Also in the industrial pole of the territories of Schio-Valdagno-Thiene the processes of transformation determined the precocious and progressive renewal of industrial buildings, favouring - between the nineteenth and twentieth centuries - the introduction of reinforced concrete with an avant-garde drive in the Veneto region, shared with a few other centres that promoted innovation, such as the Venice district - Porto Marghera and the other major cities of Verona, Vicenza and Padua.

The spread of the application in the Veneto region of the new building technique via the use of the French Hennebique patent and the activity of its concessionaire, the construction company of the engineer Giovanni Antonio Porcheddu (1860-1937) with headquarters in Turin and branches throughout Ital, was the work of a number of enlightened designers, who were in the first instance the engineer Arturo Danusso (1880-1968) (one of the designers at the Porcheddu studio from 1907 and present again in 1920) and the engineer Daniele Donghi (1861-1938) (director of the Milan branch from 1900 to 1904). In 1907, at Calvene on the Astico river (not far from Schio), Danusso built a low-arch bridge in reinforced concrete with a span of 34.5 metres with a closed tubular section; Donghi built the station flyover in Padua (1903) and in Venice a number of schools and the S. Cassiano bridge as well as designing together with Danusso the reconstruction of the St Mark's bell tower after its collapse (1910). He worked as director of the Technical Department first of one city (Padua, 18961900) and then the other (Venice, 1904-1913) [3].

The use of reinforced concrete in industrial constructions in the town of Schio was inaugurated at the very beginning of the 20th century when the French Hennebique patent was imported. This allowed the construction between 1906 and 1907 of the Cartiera Nodari (paper mill) and of the oldest part of the Lanificio Conte (woollen factory) with the characteristic shed (the plant was expanded in 1929 with a structure framed in reinforced concrete). 
Together with the surviving examples of buildings in structural reinforced masonry of the 'Manchester' type at the adjacent Rossi sites (the tall factory and Francesco Rossi woollen factory) and Conte - exceptionally significant examples of the preceding phase of the process of renewal of industrial construction - the example of the Assortissaggio offers the unrepeatable chance of to read of over one hundred and fifty years of transformation of industrial buildings in historical perspective.

The works in Schio and Valdagno built between the years 1958 and 1962 although less prestigious than the above-mentioned projects - resume the themes dear to the maestri, processing them to form an interesting synthesis. In the solution proposed for Schio and for Valdagno (an arch structure) the project presents a basic affinity - although with due differences - with the Burgo paper mill in Mantua (a structure with suspension cables) designed by the engineer Pier Luigi Nervi, which was built between 1961 and 1963 and which adopted techniques used in the construction of bridges.

The professional activity of the engineer Bruno Dall'Aglio documented in the Veneto took place during a ten year period between 1956 and 1966. During this time he worked continuously, starting from the first work, with the Ing. Pio Guaraldo construction company of Paese (operating since 1945 and still active under the name 'Ing. Pio Guaraldo S.p.A. Impresa Costruzioni'). He began with works of remarkable structural innovation, his attention being focused principally on the wide-spanning vaulted roof in reinforced concrete and the structural potential of the arch of the vault.

The first work to be completed was a bridge with a $70 \mathrm{~m}$ arch span and height of 45 metres from the surface of the water, built on the Astico river in the years 1956-1957, designed by the engineer Vittorio Ronconi, who asked Dall'Aglio to act as consultant for the definitive calculations of the arch structure.

The bridge, with a total length of 208 metres is made up of two pairs of arches - joined at the base to vertical connecting elements - which are jointed at mid section where they are fixed to the pair of viaduct beams. The result is a static design using thin structures in traditional (non prestressed) reinforced concrete that has several degrees of hyperstatic quality [7].

The arch theme is resumed in the following industrial constructions in Schio and Valdagno, built between 1958 and 1962, both based on the use of flexible arches that are then rigidified for roofs that cover spaces that are free of structural obstructions with spans of 40 and 60 metres.

The cultural climate that gave rise to these constructions was that of 'structuralism', interpreted in those years at a national level by two great protagonists: Pier Luigi Nervi and Riccardo Morandi, each having his own particular approach. In the Veneto region it was promoted, as well as by the engineer Bruno Dall'Aglio, by the convergence of figures such as the engineer Pio Guaraldo and, above all, the engineer Giandomenico Cocco, director of the technical department of the company in the years 1959-1967 and promoter of the renewal of the construction techniques in reinforced concrete and prestressed reinforced concrete. With his competence and creativity he would go on to 
become the untiring protagonist of the affirmation of wide spanning prefabricated roofs in the Veneto and at an international level.

\section{The Schio (1958-1961) and Valdagno (1961-1962) factories: a new typology of industrial construction}

As a rule it is usual to associate industrial roofing systems with the 'types' of reticular structure, either 'shed' or thin vault, that allow wide spans to be obtained thus providing flexibility of the internal distribution of the underlying spaces. Again borrowed from the first pioneering iron constructions of bridges from the beginning of the $19^{\text {th }}$ century, these types have been consolidated over the years to become the technical and compositional repertoire of modern industrial roofing.

The applications were based on the reiteration of a single structural type like the Polonceau roof truss, the reticular truss or the zero-force barrel vault conveyed by the widespread use of prefabrication, first lightweight with the introduction of metallic construction and then heavy after the spread of the use of reinforced concrete. The role of patents was crucial in this process and, in particular, of the patents that spread across Europe, including Italy, of the French Hennebique company from the last years of $19^{\text {th }}$ century and above all in the first decades of the $20^{\text {th }}$ century for the use of reinforced concrete.

In the applications that were progressively spread, the standardized solutions prevailed in correspondence with the affirmation of the industrialisation of the construction site processes and off-site prefabrication. As a result of this, creativity in structural design became limited, as did the perception of the building as a complex organism.

In regard to this approach it is difficult to 'classify' the two structures under examination in that the solutions proposed do not fall into the roof typologies mentioned. The design concept that underlies them derives, in fact, from the simultaneous application of different structural forms, that had already been consolidated by experience and approved by shared rules of calculation, for which a new interaction between the shed types and zero force arches was tried, at least for industrial roofing. The result is a spatial structure that combines longitudinal and transverse reticular beams in a synergic union of stressed and strained elements, one type compensating the other.

What the two plants of Schio and Valdagno have in common is the analogy of the structural and construction formulation that sees the integration in a loadbearing framework of a horizontal element of nerved plates supporting substantial loads and of a complex roofing system that freed the entire building from pillars.

The Schio project makes use of concrete to exalt the lightness of the building. It is made up of slender arches, which protrude above the roof, to which are hung thin window-bearing beams (figure 1). Probably the intention was to avoid the comparison between a compact structure and that of the Fabbrica Alta while giving the building an original character, and at the same time proposing an appropriate use of reinforced concrete. This problem did not arise in Valdagno 
where it was the new building itself that constituted the prominent feature of the urban skyline. The two structures evidently share the same original matrix: flexible arches made rigid by supporting a beam made up of shed structures [4-6].

Effectively there existed a previous structure from which both were derived, no longer existent, in which the shed beams were supported by a series of trapezoid frames. The transition from polygonal line (trapezium) to arch so as to increase the span while maintaining the concept of a suspended floor was a concept suggested by professor Dall'Aglio. There is, in any case, an evident and considerable evolution in the structures as they are seen today: Valdagno follows on from the Schio building, it inherited the basic designs and developed them.

The simple and precise structure of the Schio building presents an angularity that in Valdagno is 'smoothed over'; the arches are joined to the 'shoulder' while in Schio they are completely detached. In the interior, the pillars of Valdagno are inclined so as to gradually absorb the loads of the arches, while in Schio the structure is jointed directly to the vertical pillars.

The different rise ratio of the arch completes the evolution of the external appearance: in the Schio structure it is 1:4.3 while in Valdagno it is 1:5.3, with a considerable increase in the overall slenderness.

Another fundamental development is that in Schio each arch corresponds with a single shed beam (figure 2), while in Valdagno each arch has two shed beams in a balanced configuration; in this way each arch-shed can be seen as a modular system, independent and balanced. The 'rhythm' of the arches is reduced making full use of their considerable load-bearing capacity (figures 3-5).

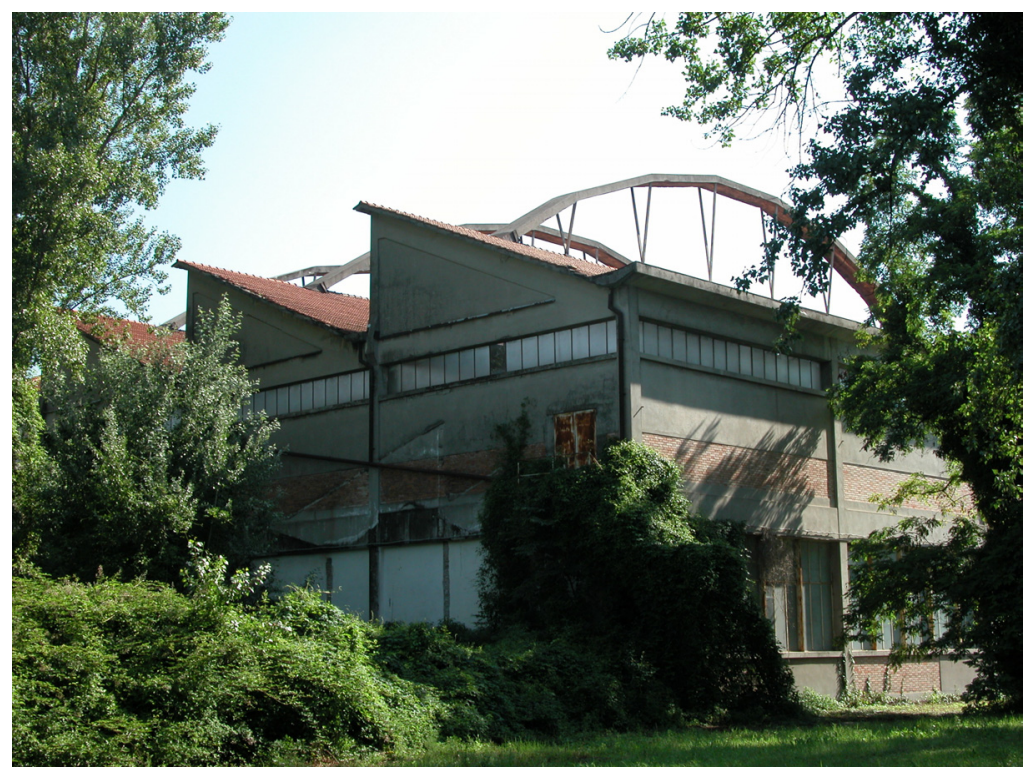

Figure 1: Schio - south view of the Assortissaggio building in Schio (photo: G. Riva, July 2007). 


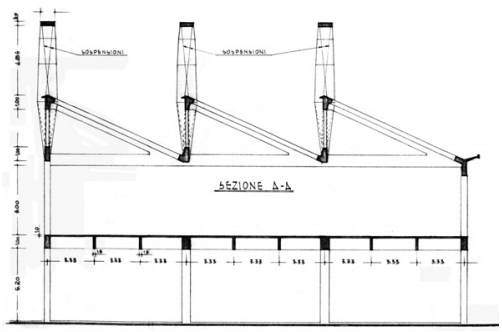

Figure 2: Schio - typical section of the structure. At the top the arches and suspended sheds can be seen.
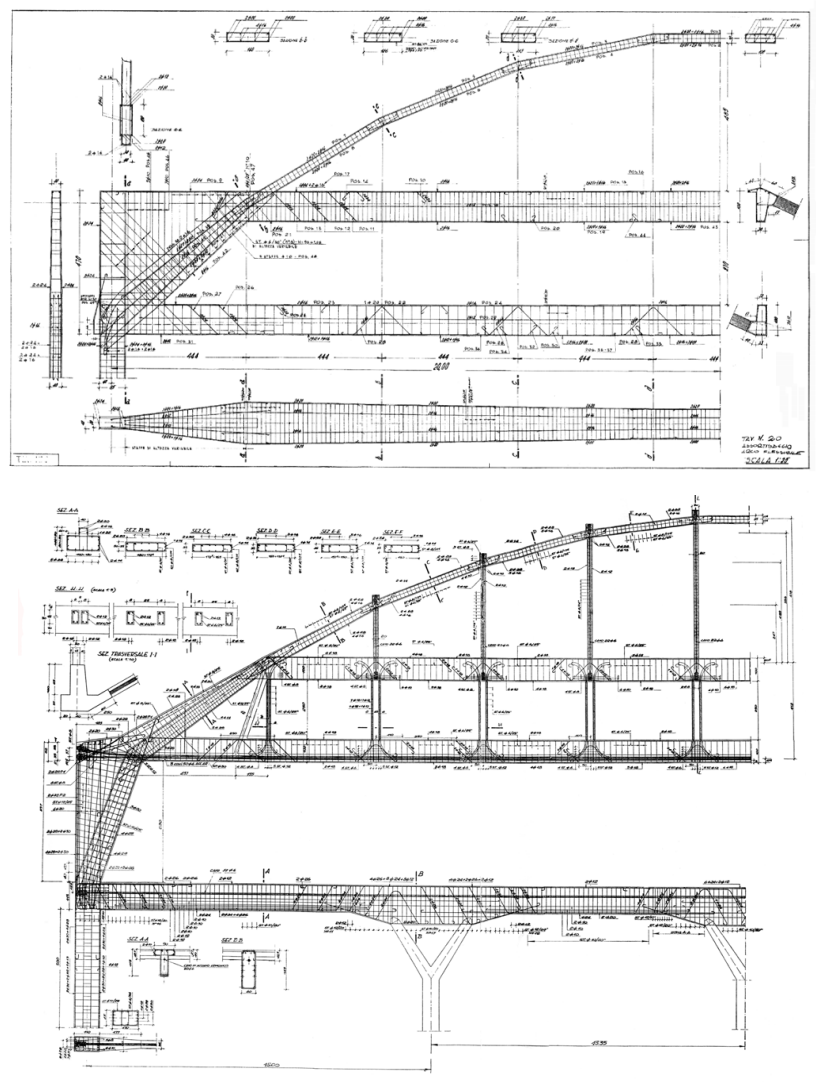

Figure 3: Comparison between the construction in Schio and the later construction in Valdagno. 

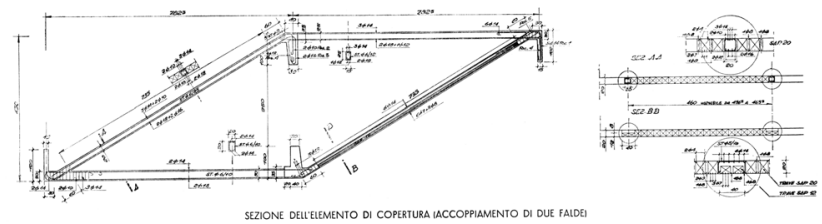

Figure 4: Valdagno - section of the roof element.

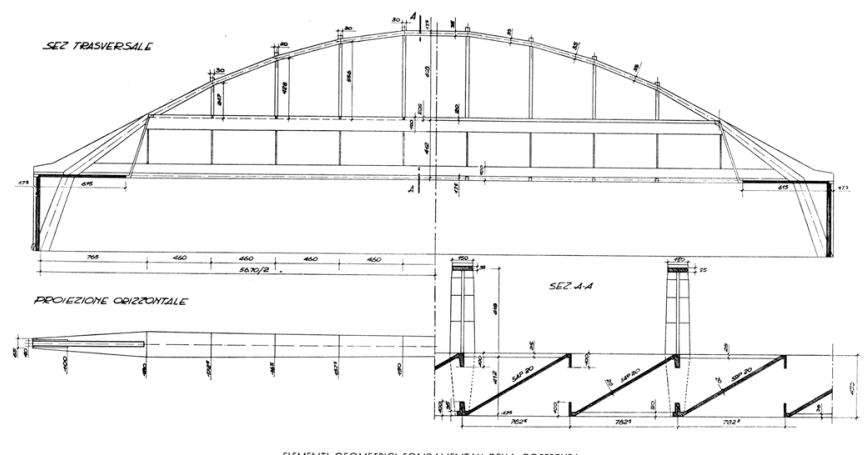

Figure 5: Valdagno - fundamental geometric elements of the roof system.

From a technological point of view it can be seen that in Schio the tie rods that connect the arches to the shed beams are simple bracing components in steel, anchored in the concrete and exposed directly to the elements, while in Valdagno they are proper prestressed tie rods in which the steel is protected and, on a structural level, the rigidity is also incremented. The connecting elements at the nodes appear to be radically changed and great care has been taken in the load diffusion areas.

In the Schio building, there is a single tie rod to take up the force of the arch, while in Valdagno there are double tie rods, again prestressed, corresponding with the upper and lower beams of the shed. In the area between the two tie rods the pillars are inclined to counteract the inclined reactions of the arches. Lengthways the slopes of the roof transfer all the longitudinal action to the lateral walls in a cross cut.

The table below indicates the principal features of the arch-beam system in the two buildings.

The materials used in both constructions are of particular interest. The types of concrete produced at the time did not exceed 35.0 to $40.0 \mathrm{MPa}$ (still evaluated experimentally by means of average values) with acceptable values in the order of 8.6 $\mathrm{MPa}$ in compression (according to the decree law of $16^{\text {th }}$ November 1939). These values were obtained with Portland cements measured out at $300 \mathrm{Kg} / \mathrm{m}^{3}$ and fine-grained river stones. Casting was carried out by specialized workers. 
The engineer Vittorio Ronconi who was co-designer with professor Dall'Aglio of the Astico bridge, in the same period, in the same area and with the same construction company, wrote:“... considering the substantial loads resulting from the calculation $\left(\sigma \mathrm{c}=85 \mathrm{~kg} / \mathrm{cm}^{2}\right)$ the production of concrete with cubic resistance at 28 days $=350 \mathrm{~kg} / \mathrm{cm}^{2}$ was deemed necessary" [7]. Later he points out "the planning and care with which the company produces the concrete: in the construction of these works... the company has consistently produced concrete with a breaking resistance from 400 to $500 \mathrm{~kg} / \mathrm{cm}^{2,}$ - a considerable achievement for the period 1956-58.

Table 1.

\begin{tabular}{|c|c|c|c|}
\hline \multicolumn{2}{|l|}{ SCHIO } & \multicolumn{2}{|l|}{ VALDAGNO } \\
\hline Arch span $[\mathrm{m}]$ & 40.00 & Arch span $[\mathrm{m}]$ & 56.70 \\
\hline Area covered per arch $[\mathrm{mq}]$ & 400.00 & Area covered per arch [mq] & 900.00 \\
\hline Arch mid-span section [m] & 9.00 & Arch mid-span section [m] & 10.76 \\
\hline Arch thickness [cm] & 30.0 & Arch thickness [cm] & 35.0 \\
\hline Average arch width [cm] & 100.0 & Average arch width [cm] & 130.0 \\
\hline Ratio thickness /span & $1 / 133$ & Ratio thickness /span & $1 / 162$ \\
\hline
\end{tabular}

On one hand, the good behaviour of the materials used in the constructions can be ascribed to the strategy adopted of not stretching their structural use to the limit - thus improving their performance while maintaining the same safety coefficient - focusing instead on exploiting the materials in the most appropriate way (compression for the concrete and traction for the steel); on the other hand their behaviour can be attributed to the reserve of strength that the concrete would acquire over time (an increase of up to $20 \%$ compared to the initial value after 28 days).

This approach was not new in the 'Italian school', which was driven from the outset by the difficulty in procuring ferrous material to fully exploit the potential of reinforced concrete for its resistance to compression and protection of the rebars without incurring the well-known problems of cracking that afflict the durability of many, more recent constructions. It allowed Giorgio Baroni in the late 1930s to create his 'umbrellas': hyperbolic paraboloids with which he was able to obtain $3 \mathrm{~cm}$-thick coverings spanning areas of $10 \mathrm{x} 10 \mathrm{~m}$, and Pier Luigi Nervi to fine tune his bold and innovative solutions in ferrocement.

\section{Evaluating new uses for the Schio building}

Professor Giovanni Luigi Fontana has proposed and obtained the collocation of the entire historic archive of the Lanerossi company within the unused spaces of the Assortissaggio plant in Schio. This meritorious initiative suggests that the 
new use will be confirmed and the conservation work on the original structure will begin shortly, and the spaces (with two obstruction-free surfaces on the ground floor and first floor of over $1,100 \mathrm{~m}^{2}$ each) within the building adapted to the new use.

The possibility of carrying out this solution follows the preliminary evaluation that the considerable load of the Archive would be borne by a structure already predisposed to support heavy loads, such as those of the product warehouse, and will also have to be assessed in the light of further theoretical and experimental on-site verifications.

The new use of the building is also compatible with the vocation of transformation of the plant (the large open space of the first floor rests on a large capacity horizontal system), provided it respects the visibility of the intrados roof with natural lighting of the internal space and the integrity of the internal volume is safeguarded.

The special feature of both buildings examined - that of being a typical expression of a 'dry' design approach of structural experts based on the buildings' function as structure capable of bearing considerable loads -suggests the main criterion for an appropriate restoration project. In short it will have to be based on one hand on respect for the original structural concept and on the conservation of the static work of the single structures (which can, if necessary, be reinforced) and, on the other hand, allowing the flow of forces that work on the structural system to remain clearly visible, even after the building has been put to a new use.

But since this solution does not resolve the delicate problem of the durability of construction typologies that expose the load bearing structures to the actions of the environment (reinforced concrete being particularly vulnerable), it will be necessary to take great care in the choice of both the most suitable treatments for controlling the phenomena of decay and the maintenance routine to be adopted in the longer term.

Regarding the energy aspects of the building's shell, the possibility of replacing the existing walls in hollow masonry blocks with an alternative capable of adapting the vertical closures to the prescribed norms must be evaluated. The thermal bridges of the 'passing' structure must be eliminated by operating on the internal side of the walls.

\section{Conclusions}

The above examples are cases of disused industrial buildings: testimonies of a 'dry' architecture in which the elevated static capabilities and the typologicalconstructional innovation at the time of their construction are evident. The buildings have the potential to enjoy a new lease of life on the strength of these qualities.

These structures are stages in the development of increasingly bold constructions that would require ever greater care in the use of materials. They acted as the driving force for the development of new concrete technologies, 
both in relation to strength as absolute value, and in relation to other physical and rheological characteristics.

They are only a first testimony of a rich, relatively recent phase in the development of constructions. However, it is precisely because these buildings are recent that they are easily forgotten and risk disappearing altogether. Many other examples of the kind are also industrial buildings: their inexorable functional obsolescence often belies the quality that distinguishes them and makes them worthy of being conserved.

\section{Acknowledgement}

We thank the engineer Giandomenico Cocco for the enthusiastic collaboration in the historical and technical analysis of these buildings.

\section{References}

[1] Iori T., Il cemento armato in Italia dalle origini alla seconda guerra mondiale, Edilstampa, Roma, 2001

[2] Poretti S., Pier Luigi Nervi, in Casabella n. 651/2, 1998

[3] Riva G., Steffinlongo F., Le prime realizzazioni in calcestruzzo cementizio armato nel rinnovamento urbano di Venezia, XIII TICCIH Congress 2006, http://www.ticcihcongress2006.net/papers_11.html

[4] Dall'Aglio B., Su un nuovo tipo di copertura a shed per edificio industriale, Università di Padova, 1961

[5] Dall'Aglio B., La copertura del nuovo salone di tessitura del Lanificio Marzotto a Valdagno, Atti dell'Istituto di Scienza delle Costruzioni dell'Università di Padova,1963

[6] Riva G., The industrial heritage of the Veneto between memory and project: what technology for conservation and reuse? Proceedings of the Fourth International Seminar on Structural Analysis of Historical Constructions, ed. C. Modena, P. B. Lourenço, P. Roca, A.A. Balkema Publishers, 2005, London, vol. I, pg.131-136

[7] Ronconi V., Viadotto sull'Astico a Rocchette (VI), - Relazione Tecnica, 30 giugno 1956 